\title{
Human mediators of the relationship between metacognitive awareness and academic achievement: parents' and teachers'support. A mediation analysis
}

\author{
ANDREA BARTA ${ }^{1}$ \\ BORBÁLA TAMÁS ${ }^{2}$ \\ ISTVÁN SZAMOSKÖZZ3
}

\begin{abstract}
From an economic point of view, it is a global problem that young people do not pursue their scientific activities after graduating from university. One of the explanations for this phenomenon is the lack of success in higher education and the inadequate information, enlightenment and motivation of students towards scientific activity. In this sense, the cognitive abilities and human resources that can increase young people's academic performance, thereby reinforcing their commitment to science, prove to be relevant. The present study included 108 psychology students from Babeș-Bolyai University who completed the Metacognitive Awareness Inventory and we recorded their academic performance (GPA), as well as the level of support offered by their parents and teachers. Our research is exploratory; in contrast with previous research, we examine not only simple linear relationships between metacognition that determines academic performance and students' social support, but also two significant human resources, parent and teacher support, as a mediator in the relationship between metacognition and academic performance. We tested three mediation models in which the predictor variable is metacognition and the outcome variable is academic perform a nce. In simple mediation models, both parental support and teacher sup port were considered significant mediators. Multiple mediation has revealed that metacognition, through the support of parents and then teachers, predicts learning achievement to a greater extent than it does in itself, without the presence of these supports.
\end{abstract}

\section{Keywords}

metacognitive awareness, social support, parents' support, teachers' sup port, academic achievement, mediation analys is

\footnotetext{
${ }^{1}$ Corresponding author, andrea.barta@ubbcluj.ro, PhD student, Babeș-Bolyai University, Evidencebased Assessment and Psychological Interventions Doctoral School, Cluj-Napoca, Romania

${ }^{2} \mathrm{PhD}$ student, Babeș-Bolyai University, Evidence-based Assessment and Psychological Interventions Doctoral School, Cluj-Napoca, Romania

${ }^{3}$ Babeș-Bolyai University, Faculty of Psychology and Educational Sciences, Department of Ap plied Psychology, Cluj-Napoca, Romania
} 